\title{
Risk Evaluation on Rural Hotel Investment and Preventive Measures
}

\author{
Xueqin Li \\ Henan Polytechnic, Zhengzhou, 450046, China
}

\begin{abstract}
: with the diversified forms of investment and development of diversified tourisms, the rural tourist attractions are built continuously and the tourism aesthetic taste and tourist interest trend are gradually improved. For the overall demand of adapting and developing the rural tourism economy and meet the diversified requirements of different tourists, it is required to deeply research the investment risk and investment environment of the rural tourism, so as to improve the construction of rural tourism facilities and the overall reception. In this paper, starting from the characteristics and reception form of rural tourism, the author evaluates the risks brought by the natural, social and economic environments of the rural hotels and briefly researches the measures taken to prevent and avoid the rural hotel investment risks.
\end{abstract}

Key words: rural hotel; rural tourism; investment risks; preventive measures Located in the rural areas, the rural hotels are dominated by the catering, accommodation, leisure and entertainment and blending with the natural environment, folk culture and village flavor, which are the places to feel the rural atmosphere and experience the rural life. The rural hotels both reflect the activity of rural culture, have the characteristics tourist spots of the rural areas, and provide the site for rural experience, and can also provide the experiencing of relevant services, which provide services like leisure, catering and accommodation to the tourists calculated by day, and the sites include clubs, resorts, hotels and rural houses etc. With the great development of economy and the maturity of market, it has become the trend that the rural tourism economy steps toward the scaled and regulated operation.

\section{Evaluation of characteristics of rural hotels in rural tourism and other reception forms}

(I) Main characteristics of rural hotels 


\section{Seasonal characteristics of rural hotels}

Restricted by the climate, natural environment and other factors, the rural hotels have the periodic and seasonal characteristics. In different seasons and climates, the natural landscapes vary greatly, and the interests of the tourists will also shift accordingly, presenting the phenomena of slack season and busy season.

2. The construction of rural hotel facilities should be based on the principle of combining artificiality and naturalness

The natural property of the rural hotels is endowed by the nature, so in the process of development, it is required to respect the natural law, blend the human creation with environment, increase practicality and make the natural environment and artificial facilities harmonious and unified.

\section{Natural hotels should have different individualities}

Compared with the urban hotels and rural home inns in service, the rural hotels has the greatest characteristic of product differentiation. The differentiation of rural hotels is reflected in some ways in the catering entertainment, environmental design and service facilities, and the local folk customs with extreme characteristics re used or improved to become the most individualized product system of the hotel.

4. Rural hotels should have rich cultural connotation

The spiritual wealth and material wealth created by the human beings during development are expressed in the form of culture. Based on tourism, the rural hotels highlight the cultural color and cultural connotation, such as national culture, building culture, clothing culture, forestry culture, fishery culture and grassland culture while reflecting the natural characteristics. It is needed to set the tourism activities and entertainment facilities with cultural characteristics in combination with the natural environment, so as to spread the local unique and rich cultures in the form of hotel.

5. Rural hotels adopt standardized and regulated management

The rural hotels are invested and conducted with the local residents, government and enterprises as the combination or unit, with the professional management mode of hotel, which both develop and inherit the rural culture and play the characteristics of standardized service of the hotel. The professional management mode is the basis for 
the sustainable development of rural hotels, and the tourists can experience the life of urban and rural areas in the rural hotels.

(II) Other tourism reception forms in addition to rural hotels

In addition to hotels, the rural tourism catering and accommodation also include the reception forms of resorts, ordinary hotels and farm home inns. Resorts are the residence groups constructed for the long-time staying travelers, which are generally developed by the tourism group enterprises, with the characteristics of harmonious nature, beautiful environment and comprehensive service, applicable to the high-end personages, and their price is also relatively expensive. The ordinary hotels have no difference from the urban hotels, there are complete hotel facilities, which can guarantee the health and safety problems. Although the ordinary hotels cannot reflect the local folk characteristics and cultural commutation. Such accommodation manner is still the main body of tourism reception. The farm home inns are the small tourism reception facilities to meet the requirements of "having dinner, living in and enjoying the farm houses" for the urban residents. The farm home inns are mainly characterized by low cost and low risks, which can both meet the requirements of the tourist to experience the folk custom and can increase the economic income of the farmers, but the adverse safety and management problems will influence the image of the tourist area.

\section{Evaluation on investment risks of rural hotels}

(I) Classification and characteristics of investment risks of rural hotels

The investment to the rural hotel is one of the investments, which will face the risks of investment and operation, and under the condition of uncertain objective condition and investment decisions, the investors will face great risks. In this paper, we summarize and categorize the classification and characteristics of investment risks.

\section{Classification of risks of investing in rural hotels}

Influenced by different environments, the investment in hotel brings opportunities while being difficult to avoid the risks. According to different standards, the risks are classified into different types. First, there exist speculation risks and pure risks: the pure risks only have the possibility of loss but not the opportunity of profit; the 
speculation risks have the possibilities of profit, loss and no loss, with coexistence of opportunity and risk. The following is the non-systematic risk and systematic risk. Systematic risk is the risk of market, inflation and interest rate jointly faced in an area; the non-systematic risk is the influence on the investment in unique item, for example, the risks brought by financial and economic management and investment mistake. Finally is the objective risk and subjective risk. The objective risk the risk which is objective and difficult to be resisted; subjective risk is the risk generated by the deviation of investment evaluation and judgment of the investors, and such risk is partial in a certain way.

\section{Characteristics of risks of investing in rural hotels}

There will be many risks of investing in the rural hotels, and the first characteristic is the uncertainty, which is reflected in the investment loss, time and space. Second, the investment risk is objective and is independent of man's will, the investors can improve the management to avoid and prevent risks. Third, the investment risk is relative in a certain way, according to the different risk bearing capabilities of different subjects, the risks will have different influences on the hotel, and there will be substantial change with the change of time and space. Finally, the investment risk is unexpected, the investment risk is a process from gradual change to qualitative change, and it is difficult to deal with the unexpected factors.

(II) Evaluation on risks of rural hotels

All indicators influencing the investment in rural hotels are dynamic, and their development and change will bring richer resources and investment environment to the rural hotels, and their uncertain factors will also bring some risks to the hotel investment. According to the sequence and weight of various qualitative changes that can influence the investment environment of rural hotels, many risks of these indicators to the rural hotels in the process of change are analyzed.

\section{Evaluation on social risks of investment in rural hotels}

The change of social and human environments will bring certain social risks to the investment in the rural hotels, including the risks brought by the local public security condition and the perception of the local residents to the tourism industry. At the 
beginning of developing tourism, the local residents hole an attitude of welcoming to the tourism development because the tourism can bring considerable income and direct economic benefit, but with the deepening and development of the tourism industry, the local living environments and folk customs will be shocked in a certain way, the residents will gradually reduce the enthusiasm to the development of tourism, and even will be dissatisfied, and this is an unavoidable change of perception, and also will become one of the risks of rural tourism. The public security risk will not only bring certain influence on the environment of rural hotel, but also bring loss to the residents and tourists, thus influencing the property and personal security, so it is required to control such risk and improve the security of the rural hotels.

\section{Evaluation on competitive risks of rural hotels}

The competitive risks are from the hotels of the same industry in the rural areas. From the perspective of weight, the scale of investment facilities should account for 0.0372 in the tourism place, on this proportion, the scale is larger and larger, the competition will be fiercer and fiercer, and the rural hotels will face greater investment risks. In the competition of the same industry, it is required to practically master the strength of the competitors in the market and the number of competitions. If the competitors have huge information network and abundant financial resources, they will greatly invest in the investment project with high value or good brand value, and the forceful competition with the competitors will cause great risks.

3. Evaluation on tourism market in the development of rural hotels

The expansion and development of tourism market bring certain opportunities for the profit of the rural hotels, and meanwhile, there exist great risks. The tourist source is the basis for the tourism market, the diversification and differentiation of tourist sources make the tourism market change continuously, and it is difficult for the tourism place to weight and decide such change. Once in case of sudden events, there will be a market risk. With the development of rural tourism economy and the construction of hotels, the number of tourists has become a main indicator for the development of hotels, and the insufficient tourists will bring considerable risk to the hotel investment. 
4. Evaluation on the existence of natural environment in the development of rural hotels

The hotel investment will bring some risks due to the change of ecological environment and natural resources, and this risk is called natural environment risk, including the crisis to the hotel by air temperature, fire, storm, flood, earthquake and other natural disasters. Although such crisis has a very low probability, it brings serious losses. Meanwhile, the rural hotels greatly depend on the natural environment, and natural environment loss will increase the risk of hotel investment. In addition, the change brought to the ecological environment by pollution and adverse environmental protection is also one of the natural investment risks. A lot of tourists will bring certain influence on the organism, atmosphere and water body in the tourism place, and waste and garbage generated continuously pollute the environment and directly influence the development of tourism and hotel cause, so it is required to take into account of the natural risks when investing in hotels.

\section{Measures for preventing risks of investing in rural hotels}

During investment, the problem that the rural hotel investors should consider is to reduce the loss of investment risk and control the risks. In this paper, analysis and research are conducted from the perspective of controlling and avoiding risks and optimizing the investment risks, so as to get several methods to control and avoid the risks:

1. It is needed to effectively preventing risks during investment in rural hotels

There will be various risks met during the hotel investment, the investment risk prevention is one of the measures taken to reduce or eliminate the risks before the risk occurring, so as to achieve the purpose of reducing loss and reducing risk occurring probability.

2. It is needed to effectively inhibiting risks during investment in rural hotels

Risk inhibition is a means to actively deal with the hotel investment risks, which is mainly aimed at the risks without early warning. During the investment in rural hotels, it is required to separate the risk unit and inhibit the risk probability. The risk units should not be concentrated in the same period and place, so as to reduce the 
probability of one-time burst of risk accident and reduce the loss brought by the risks.

3. It is needed to effectively avoid risks during investment in rural hotels

For the rural investments, it is needed to analyze the risks from the overall perspective of hotel investment on the basis of investment analysis, the investors should face the project with great investment with a prudent attitude, and the investment risk is dominated by avoiding. For the great risks, it is possible to select to give up, although this is the most passive and simplest technique, it is also the most effective and thorough risk avoiding means.

4. Emergency and retention of rural hotels in case of investment risks in investment

The loss caused by the investors' own undertaking of the risks and accidents occurring in the investment is called investment risk retention, and this method of risk avoiding is the most convenient, ordinary and simplest. In case of risk, if the risk will be increased when other steps are taken, or the expense of risk avoiding the risk loss, such risk retention method can be adopted.

Risk emergency method is a risk avoiding method forecasting the risk and established aimed at the risk process and source, i.e. to prepare the plans and tools to eliminate and control the risks in the time when and the region where risks will appear, risk emergency is an effective measures to deal with the risks without early warning. In the actual use, for the risk management procedures of rural hotels, it is required to establish the emergency plans aimed at different risks in advance to prevent order in case of risk, control the probability of sudden change of risk and reduce the risk loss.

\section{Conclusion:}

Under the context of rapid development of rural tourism, the rural hotels have higher requirements for the tourism products. integrating the advantages of farm house inns and rural inns and blending the management mechanism, facilities and services of urban hotels, rural hotels make the tourist enjoy the natural environment and the modern hotel service. However, the uncertain factors existing in the environment will cause certain risks to the investment, only by researching and correctly evaluating the investment risks and environment, realizing the seriousness of risks and effectively controlling and preventing the investment risks will it be possible to reduce the 
investment loss and increase investment income.

\section{References}

[1] Zhao Xiaolong, Wang Bing, Xing Wei, Risk Control of Hotel Investment [J], Hotel Modernization, 2012 (12).

[2] Lou Xiaohui, Research on Property Hotel Investment Risks and Avoiding Strategies [J], Modern Business Trade Industry, 2010 (06)

[3] Chen Xiaoyun, Discussion on Hotel Investment Project [J], Value Engineering, 2012 (08).

[4] Peng Hailong, Strategic Significance of Investment in Hotels [J], Enterpriser World, 2010 (12).

[5] Liu Guojiang, Research on Risk Problems of Property Hotel Investment in China

[D], Liaoning: Dongbei University of Finance and Economics, 2012 